REVISTA X, Curitiba, volume 14, n.6,p. 255-271, 2019.

\title{
O BRINCAR E A ATIVIDADE CRIADORA NO ENSINO-APRENDIZAGEM DE LÍNGUA INGLESA EM RELATO DE EXPERIÊNCIA NA FORMAÇÃO DOCENTE
}

Play and creative activity in English language teaching-learning presented in teacher education experience report

\author{
Beatriz Oliveira DELBONI(UNISO) ${ }^{1}$ \\ Daniela Ap. VENDRAMINI-ZANELLA(UNISO) ${ }^{2}$
}

RESUMO: Este estudo tem como objetivo apresentar um relato de experiência relacionado à atividade de formação docente a partir dos relatórios, que descrevem a elaboração de propostas de ensino-aprendizagem de língua inglesa, criados por alunosprofessores no Grupo Tempo de Aprender. Para isso, apresentamos algumas atividades do grupo sob os conteúdos temáticos: brincar e atividade criadora ligados à concepção vygotskyana em propostas de ensino-aprendizagem e selecionamos dois excertos advindos dos relatórios dos alunos-professores, analisando-os por meio de categorias argumentativas e os interpretando conforme conceitos revisitados em estudos bibliográficos. Mesmo partindo de breve análise e descrição, constatamos que os alunos-professores buscam dialogar teoria e prática ao discutir conceitos ligados ao ensino-aprendizagem de língua inglesa, evidenciando traços de desenvolvimento na formação docente.

PALAVRAS CHAVE: Formação docente; Brincar; Língua inglesa; Atividade criadora;

ABSTRACT: This study aims to present an experience report linked to the teacher education activity from teacher-students' academic reports, which describes the English language teaching-learning proposals, elaborated by these Time to Learn students. To accomplish this objective, we introduce some of the group's activities upon the thematical contents: play and creative activity in a vygotskyan conception in teaching learning and select two extracts arising from the teacher-students' academic reports, analyzing them from argumentative categories and interpreting them by the theoretical framework presented in this study. Even though based in brief analysis and description, we verified that the teacher-students seek to dialogue the theory and practice when discussing English language teaching-learning concepts, revealing developmental marks in teacher education.

KEY WORDS: Teacher education; Play; English language; Creative activity;

\section{INTRODUÇÃO}

\footnotetext{
${ }^{1}$ Graduanda em Letras Português/Inglês pela Universidade de Sorocaba e bolsista de Iniciação Científica PIBIC/CNPq - UNISO. E-mail: beatriz.delboni@hotmail.com

${ }^{2}$ Orientadora de Pesquisa de Iniciação Científica PIBIC/CNPq - UNISO. Doutora em Linguística Aplicada e Estudos da Linguagem pela Pontifícia Universidade Católica de São Paulo. E-mail: daniela.zanella@prof.uniso.br
} 
REVISTA X, Curitiba, volume 14, n.6, p. 255-271, 2019.

Este estudo tem como objetivo apresentar um relato de experiência relacionado à atividade de formação docente a partir dos relatórios, que descrevem a elaboração de propostas de ensino-aprendizagem de língua inglesa, criados por alunos-professores no Grupo Tempo de Aprender. Parte-se do pressuposto que os alunos-professores, ao desenvolverem propostas de ensino-aprendizagem e relatórios em que apresentam reflexões sobre os conceitos teóricos estudados, podem alcançar o diálogo 'teoria e prática'.

Para alcançarmos o objetivo supracitado, apresentamos algumas atividades do grupo sob os conteúdos temáticos: brincar e atividade criadora ligados à concepção vygotskyana em propostas de ensino-aprendizagem. Dessa organização, selecionamos dois excertos advindos dos relatórios dos alunos-professores, analisando-os por meio de categorias argumentativas e os interpretando conforme conceitos revisitados em estudos bibliográficos. Desta maneira, ao relatar a experiência do grupo e analisar os excertos, buscamos por marcas iniciais que até podem se configurar como fundamentais para o desenvolvimento da atividade de formação docente do Tempo de Aprender. Portanto, uma discussão com interpretações mais aprofundadas distancia-se do escopo deste texto, uma vez que nosso objeto é o relato de experiência que proporciona muito mais um exercício reflexivo sobre a prática que resultados de pesquisa.

O grupo Tempo de Aprender da Universidade de Sorocaba é formado por alunos-professores do curso de Letras - Português/Inglês, uma professora-formadora e uma professora-supervisora. Os alunos-professores são bolsistas do Programa de Extensão Universitária, do Programa Institucional de Bolsa de Iniciação à Docência (Pibid), de iniciativa da Capes, e de Iniciação Científica (Pibic - CNPq) que, sob orientação da mesma professora-formadora, desenvolvem pesquisas e elaboram propostas de ensino-aprendizagem de língua inglesa a serem aplicadas na escola pública.

Entre importantes conceitos que embasam as elaborações de ensinoaprendizagem, sublinha-se o brincar e a atividade criadora em perspectiva vygotskyana. Liberali (2009, p. 19) discorre sobre o conceito de brincar para Vygotsky, que está relacionado à forma de como os sujeitos participam e se apropriam da cultura de um determinado grupo social, pois durante o brincar, os sujeitos executam no plano imaginário, a capacidade de planejar, imaginar situações e representar papéis em situações sociais diversas que estão além de suas possibilidades imediatas. A partir disso, o conceito de atividade criadora do homem, considerada como aquela em que se cria 
REVISTA X, Curitiba, volume 14, n.6,p. 255-271, 2019.

algo novo, está relacionado ao brincar à medida que ele desperta a imaginação e a fantasia (VYGOTSKY, 1930/ 2009, p. 11).

Além disso, o brincar é considerado uma atividade social que se estabelece como um meio em que o sujeito age no mundo, pois pode, através do desenvolvimento de sua produção material e relações materiais, alterar sua realidade, pensando na "vida que se vive" (MARX; ENGELS, 1845-46/ 2006, p.26).

Com o enfoque no brincar e na atividade criadora, o Tempo de Aprender desenvolve elaborações de ensino-aprendizagem de língua inglesa partindo dos documentos oficiais. No período inicial de suas atividades, o grupo orientava-se pelos Parâmetros Curriculares Nacionais, PCN (BRASIL, 1998), que ressaltam como o ensino-aprendizagem de língua inglesa não se resume apenas à aprendizagem de estruturas linguísticas, mas também à experiências de vida, em que se ampliam as possibilidades de atuação discursiva do aluno no mundo (BRASIL, 1988, p. 38). Entretanto, os próprios PNCs privilegiam a habilidade de leitura, em detrimento de habilidades orais, enfatizando a leitura de literaturas técnicas, sob a seguinte justificativa:

considerar o desenvolvimento de habilidades orais como central no ensino de Língua Estrangeira no Brasil não leva em conta o critério de relevância social para a sua aprendizagem. Com exceção da situação específica de algumas regiões turísticas ou de algumas comunidades plurilíngues, o uso de uma língua estrangeira parece estar, em geral, mais vinculado à leitura de literatura técnica ou de lazer. Note-se também que os únicos exames formais em Língua Estrangeira (vestibular e admissão a cursos de pós-graduação) requerem o domínio da habilidade de leitura. Portanto, a leitura atende, por um lado, às necessidades da educação formal, e, por outro, é a habilidade que o aluno pode usar em seu contexto social imediato. Além disso, a aprendizagem de leitura em Língua Estrangeira pode ajudar o desenvolvimento integral do letramento do aluno. A leitura tem função primordial na escola e aprender a ler em outra língua pode colaborar no desempenho do aluno como leitor em sua língua materna (BRASIL, 1988, p. 20).

Nessa direção, o Tempo de Aprender norteava-se, principalmente, pelos temas propostos, trabalhados com estruturas gramaticais e leituras para que se pensasse a brincadeira. Atualmente, guia-se pela Base Nacional Comum Curricular (BNCC BRASIL, 2017), que destaca que o ensino-aprendizagem de língua inglesa deve proporcionar ao aluno novas formas de engajamento e participação em um mundo cada vez mais globalizado e plural, contribuindo para o agenciamento crítico dos estudantes e ampliando suas possibilidades de interação com o mundo. Dessa forma, a BNCC se 
REVISTA X, Curitiba, volume 14, n.6,p. 255-271, 2019.

difere dos PNCs, pois a habilidade oral torna-se fundamental, uma vez que o aluno deve experimentar diferentes formas de ser e viver no mundo.

Além disso, a BNCC confere a importância dos multiletramentos no ensinoaprendizagem de língua inglesa, que se inserem nas práticas sociais de cunho digital, em que o conhecimento da língua inglesa amplia "as possibilidades de participação e circulação - que aproximam e entrelaçam diferentes semioses e linguagens (verbal, visual, corporal, audiovisual), em um contínuo processo de significação contextualizado, dialógico e ideológico" (BRASIL, 2017, p. 242). Assim, ao se propor uma brincadeira em língua inglesa, possibilita-se a construção social de práticas de linguagem em que o aluno recombina o que já sabe com outras formas semióticas e cria algo novo.

Os conceitos do brincar e da atividade criadora serão abordados no primeiro item deste texto. Na sequência, apresentamos os procedimentos metodológicos para coleta e análise de dados. Também, a descrição do grupo Tempo de Aprender e de algumas atividades ligadas aos conteúdos temáticos: brincar e atividade criadora, em perspectiva vygotskyana, como as propostas de ensino-aprendizagem e os relatórios dos alunos-professores sobre as atividades. Dessa organização, selecionamos dois excertos advindos dos relatórios, analisando-os por meio de categorias argumentativas e os interpretando conforme conceitos revisitados em estudos bibliográficos. Por último, são tecidas reflexões sobre as possíveis ressignificações na atividade de formação docente no Grupo Tempo de Aprender.

\section{O BRINCAR E A ATIVIDADE CRIADORA}

O brincar apresenta-se como um conceito amplo e, por isso, ressalta-se que, neste estudo, será tratado dentro da perspectiva sócio-histórico-cultural. A Teoria da Atividade Sócio-Histórico-Cultural (TASHC) foi elaborada a partir dos estudos de Vygotsky (1933/1998), Leontiev (1977) e Engeström (1999), e abrange que os sujeitos, historicamente, constituem a si mesmos e aos demais por meio de relações que são mediadas socialmente (VENDRAMINI-ZANELLA; LIBERALI, 2011, p. 96).

É fundamental entender as raízes marxistas que influenciaram a TASHC, pois o contexto que o autor estava inserido não pode ser desvinculado de suas ideias (SANTA; BARONI, 2014, p. 2). Com base no materialismo histórico-dialético de Marx (1818 1883), o trabalho é a atividade em que o homem cria a si mesmo, se constitui como 
REVISTA X, Curitiba, volume 14, n.6,p. 255-271, 2019.

sujeito. Assim, a atividade humana é como o sujeito age no mundo, criando sua história, ou seja, pensando na "vida que se vive” (MARX; ENGELS, 1845-46/ 2006, p. 26).

O brincar pode ser considerado como uma atividade social, pois necessita de contextos sociais e culturais, em que, a partir desses fatores, o sujeito recria a sua realidade e pode alterá-la (WAJSKOP, 1995, p. 28). Quando se fala no brincar, compreende-se os jogos, a imaginação, a fantasia, o faz-de-conta, a encenação, o prazer e o divertimento, pode-se considerar o brincar livre, o brincar regrado e a performance, tanto a livre como a com script (VENDRAMINI-ZANELLA; LIBERALI, 2011, p. 97). A partir disso, o conceito de atividade criadora do homem, considerada como aquela em que se cria algo novo, está relacionado ao brincar à medida que ele desperta a imaginação e fantasia (VYGOTSKY, 1930/ 2009, p. 11).

O brincar livre está relacionado ao faz-de-conta e à fantasia durante a primeira infância (HOLZMAN, 2009, p. 50), já o brincar regrado está ligado aos jogos, que são atividades mais estruturadas e governadas por regras explícitas, sendo a forma predominante quando se fala do brincar relacionado aos adultos (NEWMAN; HOLZMAN, 1993/2002, p. 113; HOLZMAN, 2009).

Compreendida no brincar, a performance é uma abordagem defendida por Holzman (2009) e utilizada na criação de situações que expressam desejos, pensamentos e ambições que ainda estão no plano imaginário. Por meio da performance de situações sociais, é proporcionado um momento de reflexão ao aluno. No estudo de VendraminiZanella e Liberali (2011), por exemplo, as crianças desenvolvem uma performance tomando como base a atividade social "brincar de ir à piscina e nadar", que é realizada no corredor de um hospital infantil. Nesse caso específico, por estarem em contexto hospitalar, ir à piscina e, ainda, brincar com água, eram provavelmente apenas sonhos para aquelas crianças que estavam em tratamento.

Dessa forma, o brincar proporciona experiências além das possibilidades imediatas e contribui para que os alunos percebam outras formas de atuar no mundo, despertando também a atividade criadora (LIBERALI, 2009, p. 19). É fato que tudo que foi criado pelo ser humano é fruto do que um dia só estava em sua imaginação. Sendo assim, pela imaginação e atividade criadora, é possível que o sujeito altere o seu presente e transforme a realidade em que está inserido.

Conforme Vendramini-Zanella (2018), a atividade criadora configura-se de duas formas na perspectiva vygotskyana: a reprodutiva, em que reconstitui algo, e a criadora, 
REVISTA X, Curitiba, volume 14, n.6,p. 255-271, 2019.

em que se combina algo. Assim, para Vygotsky (1930/2009), a atividade reprodutiva está ligada à conservação das experiências anteriores, à repetição de hábitos permanentes e de condutas já formadas e criadas anteriormente.

É possível relacionar a atividade criadora com o conceito de ZPD (Zona de Desenvolvimento Proximal), também desenvolvido por Vygotsky (1930/ 2009). Essas zonas de possibilidades futuras propiciam a representação de papéis que estão além da possibilidade imediata do sujeito. Nas palavras de Malta,

[...] Holzman (2002) aponta que a ZPD é a distância entre ser e tornar-se, sempre emergente e em constante mudança, pois quando em zonas de desenvolvimento, fazemos coisas que ainda não dominamos; vamos além de nós mesmos (MALTA, 2015, p. 67).

Assim, a Zona de Desenvolvimento Proximal (ZPD) pode ser definida como um espaço, que caracteriza o que os participantes são e o que estão tornando-se. Esse espaço envolve uma participação colaborativa dos indivíduos, que irão criar novos significados juntos (MAGALHÃES, 2009, p. 59). Portanto, Vygotsky defende que os processos de aprendizagem e desenvolvimento devem ser dialéticos e históricos, sendo construções coletivas e não processos que foquem apenas no indivíduo em si (MAGALHÃES, 2009, p. 61).

O brincar é influenciado também pelas situações que o sujeito vivenciou até o momento, pois é uma combinação criativa das impressões já vivenciadas por ele, que pode gerar algo novo e despertar a atividade criadora (VYGOTSKY, 1930/ 2009, p. 17). Desse modo, é com Vygotsky que o brincar passa a ser essencial para melhor compreensão, por parte do aluno, da sua vida e do ambiente em que está inserido.

Uma vez que, para Vygotsky (1930/ 2009, p. 22), a lei fundamental que rege a atividade da imaginação é a de que a experiência é essencial, pois constitui o material que será usado para a construção de novas ideias e das fantasias, portanto, deve ser apresentado ao aluno diversos artefatos culturais para que ele possa ter mais experiências e possa, assim, aumentar sua atividade de criação. Na visão de Malta (2015, p. 53), quando se utiliza o brincar para proporcionar e imaginar situações novas, o aluno se vê livre da sua condição limitadora do momento. O brincar torna-se libertador para o sujeito.

É por esses fatores que o brincar pode ser uma alternativa de ensinoaprendizagem, já que colabora para que o aluno assuma papéis que vão além da sua limitação no momento, utilizando a imaginação e a atividade criadora. Por isso, o 
REVISTA X, Curitiba, volume 14, n.6,p. 255-271, 2019.

brincar em proposta de ensino-aprendizagem de língua inglesa pode possibilitar ao aluno planejar, imaginar situações e representar papéis além de si mesmo (HOLZMAN, 2009).

\section{OS PROCEDIMENTOS DE COLETA E ANÁLISE DE DADOS}

Este texto apresenta um relato de experiência relacionado à atividade de formação docente a partir dos relatórios, que descrevem a elaboração de propostas de ensino-aprendizagem de língua inglesa, criados por alunos-professores no Grupo Tempo de Aprender.

Como procedimentos metodológicos, iniciamos pela descrição do contexto de formação docente e apresentamos algumas propostas de ensino-aprendizagem de língua inglesa elaboradas pelos alunos-professores sob orientação da professora-formadora que demarcassem o brincar e a atividade criadora em seus conteúdos. Na sequência, apresentamos dois excertos advindos dos relatórios sobre essas propostas de ensinoaprendizagem. Para a análise por meio de categorias argumentativas, focalizamos nos aspectos enunciativos, discursivos e linguísticos, com base em perspectiva proposta por Liberali (2013).

Para a produção, coleta, organização e armazenamento dos dados foram seguidos os princípios éticos da universidade no Comitê de Ética da Universidade de Sorocaba http://uniso.br/pesquisa/cep/ acessado em Maio de 2019) ${ }^{3}$.

Nas questões enunciativas, identificamos o local e o momento de produção, recepção e circulação das experiências, bem como o papel social dos envolvidos na produção dessas. Em relação às questões discursivas, analisamos a organização e a articulação do texto e os "tipos de argumentos" que são introduzidos nos enunciados dos alunos-professores ao apresentarem uma elaboração caracterizada pela intenção em estabelecer um contrato com o outro na tentativa de sustentar seu ponto de vista (PERELMAN \& OLBRECHTS- TYTECA, 1958/2005). Para maior entendimento desse conceito, colocamos o 'tipo de argumento de exemplo' em que se menciona um fato ou caso anterior, para confirmar a ideia que se está sustentando. Finalmente, quanto às questões linguísticas, ressaltamos as escolhas lexicais e operadores argumentativos (por exemplo: mas, porém), conectando-as aos conceitos discutidos na revisão da literatura.

\footnotetext{
${ }^{3}$ CAAE: 58314516.1000 .5500 (03/08/2016). Título da pesquisa: A argumentação na formação docente.
} 
REVISTA X, Curitiba, volume 14, n.6, p. 255-271, 2019.

Por último ainda sobre a análise, os nomes dos alunos que aparecem no recorte são substituídos por suas iniciais.

\section{Descrição do contexto}

Neste estudo, o contexto de formação docente focaliza-se nas atividades do Tempo de Aprender que, como apresentado brevemente na introdução, é um grupo da Universidade de Sorocaba formado por alunos-professores do curso de Letras Português/Inglês (bolsistas do Programa de Extensão Universitária, do Programa Institucional de Bolsa de Iniciação à Docência, Pibid/ Capes e de Iniciação Científica Pibiq/CNPq e Probic/bolsa institucional), uma professora-formadora e uma professorasupervisora. Desse modo, parte-se da leitura dos relatórios dos alunos-professores que relatam suas experiências adquiridas no projeto e descrevem suas atuações enquanto professores em formação. Assim, os relatórios apresentam, sob perspectivas individuais, o processo e resultados de ações coletivas do Tempo de Aprender, tanto com características acadêmicas, como extensionistas e teórico-práticas.

Criado no ano de 2009, o Grupo Tempo de Aprender originou-se por ações extensionistas, em uma escola pública. Em 2014, o Pibid/ Capes (Uniso) de língua inglesa, sob coordenação da professora-formadora do Tempo de Aprender, foi integrado ao grupo. Articulado pela parceria universidade-escola, o Pibid promove a vivência teórico-prática aos alunos-professores. Por último, em 2015, foi a vez de os bolsistas do Programa de Iniciação Científica da Uniso se integrarem ao Tempo de Aprender, concedendo ao grupo o perfil mais acadêmico. Portanto, o Tempo de Aprender constituiu-se em um espaço de produção de novos conhecimentos, intercâmbio de saberes, com o objetivo de pensar e repensar a prática de todos os envolvidos.

O objetivo central da atividade de formação dentro do Tempo de Aprender é promover o diálogo entre teoria e prática no que se refere a conceitos de ensinoaprendizagem e orientar o aluno-professor para estabelecer esse diálogo, possibilitando que se tornasse autônomo e elaborador de suas aulas, de suas propostas de ensinoaprendizagem e de seus relatórios acadêmicos. Por isso, a relevância em acompanhar esse momento da prática pedagógica, transformando-o num momento em que se ultrapasse as ações espontâneas e permeadas pelo senso comum para se chegar "a uma esfera crítica na qual a realidade se dá como objeto cognoscível e na qual o homem assume uma posição epistemológica" (FREIRE, 1980, p. 26). Nesse contexto, sublinhase a possibilidade de vivenciar a sala de aula e desenvolver as propostas de ensino- 
REVISTA X, Curitiba, volume 14, n.6,p. 255-271, 2019.

aprendizagem com os alunos da rede pública tendo como ponto de partida os projetos e discussões na universidade.

Nessa junção de programas em um grupo, tantos os encontros de formação como as orientações para a elaborações se realizam de forma integrada, mesmo que cada programa possua objetivos distintos. Dessa maneira, entre as atividades previstas nos encontros de formação docente do Tempo de Aprender, coloca-se em relevo as discussões sobre leituras teóricas, a elaboração de propostas de ensino-aprendizagem de língua inglesa e de relatórios parciais e finais sobre suas atividades.

Para compreender de que forma os excertos em análise foram selecionados dos relatórios alunos-professores, faz-se necessário apresentar algumas atividades do grupo, delinear os objetivos específicos, exigências e tempo de duração de cada programa que compõe o Tempo de Aprender. Ressaltamos que para este estudo, as atividades selecionadas estão circunscritas sob os conteúdos temáticos: brincar e atividade criadora ligados à concepção vygotskyana em propostas de ensino-aprendizagem, a conforme se expõem a seguir:

Tabela 1: Objetivos dos Programas inseridos no Tempo de Aprender

\begin{tabular}{ll}
\hline PROGRAMA & PRINCIPAL OBJETIVO/ EXIGÊNCIAS/ DURAÇÃO \\
PROBEX & Por meio de ações extensionistas ligadas à vivência \\
& comunitária, elaborar propostas de ensino-aprendizagem \\
& de língua inglesa pelo brincar. /Entre as exigências, os \\
& bolsistas do Probex entregam um relatório parcial e um \\
& final a partir de suas experiências em campo e \\
& apresentam resultados em encontro de pesquisadores. \\
& Esse programa tem duração de um ano (início em \\
& Agosto/ término em Junho). \\
& Sob uma ótica teórico-prática, estudar, planejar e \\
& desenvolver propostas de ensino-aprendizagem de língua \\
inglesa pelo brincar. /Entre as exigências, os bolsistas do & Pibid/ Capes entregam um relatório parcial e um final \\
& com base em suas vivências em campo. Esse programa \\
& pem duração de um ano (início em Fevereiro) com a \\
&
\end{tabular}


REVISTA X, Curitiba, volume 14, n.6,p. 255-271, 2019.

PIBIC CNPq e Probic/ Por um viés acadêmico, pesquisar e discutir o conceito institucional do brincar inserido no ensino-aprendizagem de língua inglesa. /Entre as exigências, os bolsistas de Iniciação Científica entregam um relatório parcial e um final, por meio de pesquisa bibliográfica, e apresentam resultados em encontro de pesquisadores. Esse programa tem duração de um ano (início em Agosto/ término em Junho).

Fonte: tabela elaborada para o estudo pelas autoras.

A partir de perspectivas distintas, ora extensionista, ora teórico-prática, ora acadêmica, o Tempo de Aprender compartilha de um objeto comum: considerar o brincar e a atividade criadora na concepção vygotskyana inseridos nas elaborações e discussões. Assim, a cada novo bolsista, diferente brincadeira surge. A seguir, selecionamos algumas atividades a partir dos conteúdos temáticos: brincar e atividade criadora:

Tabela 2: As diferentes brincadeiras nas propostas de ensino-aprendizagem de língua inglesa elaborações - Probex e Pibid/ Capes, Tempo de Aprender.

\begin{tabular}{ll}
\hline ANO & BRINCADEIRAS EM PROPOSTAS DE \\
& ENSINO-APRENDER \\
& Brincar de cup song e brincar de restaurante. \\
2014 & Brincar de curling; brincar de ir à biblioteca; \\
& brincar de predictions e brincadeiras de rua. \\
& Brincar de viajar em um cruzeiro; brincar de fazer \\
& um piquenique e brincar de participar de uma \\
& gincana. \\
& Brincar de empreendedor; brincar de participar de \\
& uma manifestação e brincar de cápsula do tempo. \\
& Brincar de criar avatares e brincar de produzir \\
& curtas metragens.
\end{tabular}

Fonte: tabela elaborada para o estudo pelas autoras. 
REVISTA X, Curitiba, volume 14, n.6,p. 255-271, 2019.

A seguir, apresentamos as atividades acadêmicas do Programa de Iniciação Científica:

Tabela 3: Pesquisas de Iniciação Científica sobre o conceito do brincar e atividade criadora no ensinoaprendizagem de língua inglesa - PIBIC e PROBIC, Tempo de Aprender.

\begin{tabular}{ll}
\hline ANO & TÍTULO DA PESQUISA \\
2015 & O brincar em proposta de ensino-aprendizagem \\
& de língua inglesa por meio de Atividade Social. \\
2016 & Organizador curricular de ensino-aprendizagem \\
& de língua inglesa por meio de Atividade Social. \\
2017 & O ensino-aprendizagem na perspectiva sócio- \\
& histórico-cultural. \\
& O brincar em proposta de ensino-aprendizagem \\
& de língua inglesa. \\
& O ensino-aprendizagem de língua inglesa na \\
& perspectiva sócio-histórico-cultural. \\
\hline
\end{tabular}

Fonte: tabela elaborada para o estudo pelas autoras.

Interligadas à essas elaborações (propostas de ensino-aprendizagem e pesquisas), os alunos-professores do Tempo de Aprender desenvolvem relatórios parciais e finais em que se evidencia os conteúdos temáticos: brincar e atividade criadora. Desse recorte temático, selecionamos dois excertos.

Assim, o contexto em que as atividades são realizadas é a escola pública, em aulas de língua inglesa, configurando-se como um espaço de vivência onde os alunosprofessores têm a possibilidade de desenvolver o que é discutido e planejado na universidade. Os alunos-professores participaram de forma supervisionada e orientada, colocando em relevo o protagonismo almejado no interior da formação docente.

\section{Análise e discussão}

Conforme já mencionado, os excertos são selecionados dos relatórios dos alunos-professores em busca de traços de desenvolvimento na formação docente quando 
REVISTA X, Curitiba, volume 14, n.6,p. 255-271, 2019.

demostram dialogar, de forma teórico-prática, os conceitos do brincar e da atividade criadora em viés vygotskyano.

No primeiro excerto, apresenta-se uma seleção do relatório da aluna-professora T.A. (Programa Pibid/ Capes, 2015) em que descreve a brincadeira de Predictions. Essa aluna-professora iniciou sua participação no grupo no início de 2015, permanecendo até junho de 2016.

Já no dia 23 de novembro, utilizamos esses textos para brincar com os alunos em um jogo muito parecido com o Perfil, jogo de tabuleiro no qual você ouve as características de alguém e deve adivinhar de que pessoa se trata perfeito. Os alunos foram divididos em dois grupos e cada um teve que usar um chapéu com o nome de algum colega, o qual deveria adivinhar. Sua equipe lia as características da pessoa e o aluno ganhava pontos de acordo com o total de dicas que recebeu até conseguir adivinhar. (tipo de argumento de exemplo). No começo do jogo do dia 23, os alunos estavam com receio de participar. Mas, (operador argumentativo) depois viram como a brincadeira funcionava, ficaram animados e até queriam usar o chapéu e tentar adivinhar novamente.

Para Liberali (2009), o brincar cria a base para a integração com a vida, pois se organiza como uma atividade que recria as atividades da vida para permitir sua apropriação. Pensando assim, achei muito interessante o fato de as equipes estarem fazendo mímica para os amigos tentarem adivinhar, assim não precisavam falar as dicas em português (apresentação de ponto de vista). Eles não burlaram nenhuma regra e conseguiram criar uma forma criativa de se comunicarem, além das dicas em inglês.

\section{Excerto 1}

No início do excerto 1, verificamos que a aluna-professora T.A. embasa-se no conceito vygotskyano do 'brincar regrado' e isso se justifica ao passo que atua no Ensino Fundamental 2, fase em que as regras apresentam papel essencial no desenvolvimento e aprendizagem dos alunos. Nesse contexto escolar em que T. A. direciona sua brincadeira, o que antes era regido pela fantasia, passa a ser guiado pelas regras, e isso pode ser constatado nas escolhas lexicais "tabuleiro”, "preocupação", o próprio sintagma "brincar regrado", "ganhava pontos" como uma das formas de organização via regras, e especificamente a palavra "regra", entre outras.

Também, a aluna-professora T.A. organiza seu texto discursivamente de forma argumentativa apresentando 'tipo de argumento de exemplo' ao comentar como os alunos foram dispostos em grupos e ao descrever as regras do nome do chapéu entre outras questões. Além disso, utiliza o operador argumentativo "mas" demarcando uma 
REVISTA X, Curitiba, volume 14, n.6,p. 255-271, 2019.

oposição em sua construção para sustentar suas ideias. Finalmente, a aluna-professora conclui com apresentação de um ponto de vista e expõe suas conexões sobre a atividade criadora e a prática na escola pública, de maneira fundamentada em leitura teórica: "não burlaram nenhuma regra e conseguiram criar uma forma criativa de se comunicarem, além das dicas em inglês."

Ao interligar teoria e prática sobre o conceito do jogo, que está inserido no brincar em perspectiva sócio-histórico-cultural, a aluna-professora apresenta marcas sobre formas de elaboração de propostas de ensino-aprendizagem de língua inglesa, experimentando uma alternativa que colabora para o aluno assumir papéis que vão além da sua limitação no momento, utilizando a imaginação e a atividade criadora. Resgatamos Holzman (2009) para inferir que ao representar papéis além de si mesmo, esses alunos podem ir se tornando por se permitirem ser.

O segundo excerto selecionado é da aluna-professora, Q., (Programa Pibid/ Capes, 2015) cuja brincadeira foi o curling (esporte de olimpíada de inverno). Essa aluna Q. iniciou sua participação no grupo no início de 2014 e permaneceu até o final de 2015.

A atividade Curling, além de trabalhar a escrita e a conversação em inglês, ainda propiciou o conhecimento de um esporte muito diferente, o Curling, e desenvolveu os gêneros "programa de TV" e "entrevista" com os alunos. Eles teriam que pensar, por exemplo, qual é a estrutura e aspectos do texto de um programa televisivo para apresentar a história do esporte, como é o texto de uma entrevista e suas características, qual a duração de um programa (tipo de argumento de exemplo). Em poucos dias aprendi muito sobre a vivência na sala de aula. Eu nunca tive essa experiência antes e agora acho que eu teria muita dificuldade em entrar pela sala de aula como professora sem ter esse preparo. Nós, futuros educadores, já conseguimos perceber como os alunos aprendem mais sobre o que eles se interessam, o que eles gostam. Como por exemplo, o trabalho com gêneros, tanto na entrevista lida na atividade sobre Predictions, quanto no programa de TV feito na atividade de Curling (tipo de argumento de exemplo). Por coincidência, aprendi nesse semestre, na faculdade, sobre o ensino-aprendizagem pautado em gêneros, e pude ver essa prática através do PIBID. Os alunos realmente se interessam mais por uma entrevista, que utiliza $I$ will, I would like to, do que por uma lista dessas frases. $\mathrm{O}$ gênero torna $\mathrm{o}$ aprendizado mais prazeroso e quase imperceptível (quem percebe que estamos aprendendo Future Tense, Past Tense, etc, numa entrevista?).

\section{Excerto 2}


REVISTA X, Curitiba, volume 14, n.6,p. 255-271, 2019.

$\mathrm{Na}$ abertura deste excerto, constatamos a preocupação em se trabalhar questões de ensino-aprendizagem atreladas à brincadeira e à atividade criadora, marcada pelas escolhas lexicais: "escrita”, “conversação em inglês", "gêneros”, "estrutura e aspectos de...".

Ainda, a aluna-professora expõe um 'tipo de argumento de exemplo' que expande a construção de sua ideia, sustentando o que defende. Ao desempenhar o papel de aluna-professora elaboradora de proposta de ensino-aprendizagem, Q. possibilita o despertar da imaginação aos alunos que, a partir da brincadeira daquilo que não faz parte de seus contextos - o curling - organizam-se a criar algo novo; em um viés vygotskyano de atividade criadora.

Na sequência, a aluna-professora enuncia impressões sobre a formação docente dizendo que, mesmo que inicial, já percebe os ganhos de se ter a vivência em contexto escolar como laboratório de atividade prática. Materializando linguisticamente pelas escolhas lexicais: "aprendi muito", "vivência na sala de aula," "experiência", "dificuldade", "professora", "preparo", a aluna-professora demarca seu desenvolvimento e aponta indícios sobre o papel professor em inserir os interesses dos alunos nas aulas: "Nós, futuros educadores, já conseguimos perceber como os alunos aprendem mais sobre o que eles se interessam, o que eles gostam”.

Para sustentar seu ponto de vista sobre a importância em se considerar o interesse do aluno na elaboração de aulas, Q. utiliza o 'tipo de argumento de exemplo': (...) Como por exemplo, o trabalho com gêneros, tanto na entrevista lida na atividade sobre Predictions, quanto no programa de TV feito na atividade de Curling". Argumentativamente, o esforço em se exemplificar o que expõe, marca, de certa forma, seu processo de formação docente em visualizar como se executa algo na prática.

Por último neste excerto, a aluna-professora Q., mais uma vez, interliga as descrições sobre a atividade prática - brincar de curling - com saberes relacionados ao ensino-aprendizagem de língua inglesa, que podemos constatar em: "ensinoaprendizagem”, "gêneros", "entrevista”, "I will”, "I would like to", "frases”, "Future Tense, Past Tense”. Por se dedicar em inserir o brincar e a atividade criadora na apropriação de pontos gramaticais e gêneros, verificamos que a aluna-professora alinhase à BNCC (BRASIL, 2017) que frisa que o ensino-aprendizagem de língua inglesa é responsável por oferecer possibilidades de participação social e engajamento em um 
REVISTA X, Curitiba, volume 14, n.6,p. 255-271, 2019.

mundo mais diversificado e multicultural, assim, corroborando para o agenciamento crítico dos alunos.

Um dos principais pontos visto nos excertos é a tentativa de se inserir o brincar como uma alternativa na elaboração de propostas de ensino-aprendizagem de língua inglesa, por viabilizar: o processo de uma atividade criadora.

Além disso, verifica-se que, a partir da leitura dos relatos que o brincar nas propostas de ensino-aprendizagem permite formas semióticas de se criar algo, alinhadas à perspectiva dos multiletramentos, prevista na BNCC (BRASIL, 2017), pelas suas possibilidades de uso da linguagem verbal, visual, corporal e audiovisual. Por último, o documento oficial BNCC aborda aspectos como: perceber a si mesmo e aos outros como parte integrante, ativa e pertencente a um mundo plurilíngue; articular os aspectos culturais, sociais e identitários, superar a visão tecnicista de aprendizagem de línguas; valorizar a multiculturalidade entre outros (SANTOS, 2019), questões em consonância com o brincar entendido neste estudo.

Assim, podemos dizer que mesmo que de forma inicial, os alunos-professores estejam em um processo de se criticizar que, em viés freiriano, assumem uma posição embasada teoricamente para explicar o que fora vivenciado na prática.

\section{CONSIDERAÇÕES FINAIS}

Este trabalho objetivou apresentar um relato de experiência relacionado à atividade de formação docente a partir dos relatórios, que descrevem a elaboração de propostas de ensino-aprendizagem de língua inglesa, criados por alunos-professores no Grupo Tempo de Aprender. Para tanto, apresentamos algumas atividades do grupo sob os conteúdos temáticos: brincar e atividade criadora ligados à concepção vygotskyana em propostas de ensino-aprendizagem e selecionamos dois excertos advindos dos relatórios dos alunos-professores, analisando-os por meio de categorias argumentativas e os interpretando conforme conceitos revisitados em estudos bibliográficos.

A partir da descrição do contexto e da análise desses dois excertos, constatamos que é possível promover um diálogo entre teoria e prática de conceitos relacionados ao brincar e à atividade criadora no ensino-aprendizagem de língua inglesa e, portanto, apresentar traços de desenvolvimento na formação docente.

Assim, por meio desse relato de experiência, podemos compreender a importância de desenvolver a autonomia dos alunos-professores, uma vez que, a partir 
REVISTA X, Curitiba, volume 14, n.6,p. 255-271, 2019.

de conceitos sobre o brincar e a atividade criadora na concepção vygotskyana relacionados ao processo de ensino-aprendizagem, eles se tornaram elaboradores de suas aulas e exercem papel de protagonismo.

\section{REFERÊNCIAS}

BRASIL. Ministério da Educação. Base Nacional Comum Curricular. 2017.

BRASIL, MEC. Parâmetros Curriculares Nacionais. Ensino de quinta a oitava séries: Língua Estrangeira. diretrizes_curiculares_nacionais_2013.pdf Acesso em Dezembro, 2014.

ENGESTRÖM, Y. Activity Theory and individual and social transformation. In:

MIETTINEN, R.; PUNAMÄKI, R.-L. (Ed). Perspective on Activity Theory. Cambridge: Cambridge University Press, 1999. p. 19-38.

FREIRE, P. Conscientização: teoria e prática da libertação - uma introdução ao pensamento de Paulo Freire. $3^{\text {a }}$. edição. São Paulo: Cortez \& Moraes, 1980.

HOLZMAN, Lois. Vygotsky at work and play. New York: Routledge, 2009.

LIBERALI, F. C. Argumentação em Contexto Escolar. Campinas, SP. 2013.

Atividade social nas aulas de língua estrangeira. São Paulo: Ed. Richmond, 2009.

LEONTIEV, A. N. Activity, consciousness, and personality. Englewood Cliffs, NJ: Prentice Hall, 1977.

MARX, K.; ENGELS. F. A Ideologia alemã: teses sobre Feuerbach. São Paulo: Centauro Editora, 2006. [1845-46]

O Capital: crítica da economia política. Livro primeiro, Tomo I. Tradução Regis

Barbosa e Flávio R. Kothe. São Paulo: Abril Cultural, 1996. <http://www.marxists.org/portugues/marx/1867/ocapital-v1/index.htm >Acessado em junho de 12. [1867].

MALTA, S. Aprender brincando em língua estrangeira: uma perspectiva dos multiletramentos na educação infantil. 2015. 224 f. Dissertação (Mestrado em Linguística) - Pontifícia Universidade Católica de São Paulo, São Paulo, 2015.

NEWMAN, F.; HOLZMAN, L. (1993) Lev Vygotsky: cientista revolucionário. Tradução de Marcos Bagno. São Paulo: Edições Loyola, 2002.

PERELMAN, C.; OLBRECHTS-TYTECA, L. Tratado da argumentação: a Nova Retórica. Tradução Maria Ermantina de Almeida Prado Galvão. São Paulo: Martins Fontes, $2^{\mathrm{a}}$ ed., 2005. [1958].

SANTA, Fernando Dala e BARONI, Vivian. As raízes marxistas do pensamento de Vigotski: contribuições teóricas para a psicologia histórico-cultural. Marília: Kínesis, vol. VI, n. 12, p.1-16, dezembro 2014. 
SANTOS, E.R. Atividades sociais e multiletramentos nas aulas de língua inglesa do ensino fundamental I: uma proposta de práticas pedagógicas para compartilhamento na formação docente.2019. 186f. Dissertação (Metrado Profissional em Educação: Formação de Formadores). Pontifícia Universidade Católica de São Paulo, São Paulo, 2019.

VENDRAMINI-ZANELLA, D. A. Reprodução de orientações na constituição das atividades de formação docente em cadeia criativa. In: LIBERALI, F. \& FUGA, V.(Orgs.). Cadeia Criativa: teoria e prática em discussão. $1^{\mathrm{a}}$. ed. Campinas: Pontes, 2018, v.1, p. 187-213.

e LIBERALI, Fernanda Coelho. Brincar no hospital: uma produção criativa na formação de alunos-educadores. In: Linguagem \& Ensino, Pelotas, Vol. 1, No. 14, 11. jan./jul. 2011.

VYGOTSKY, L. S. A formação social da mente. 6. ed. São Paulo: Martins Fontes, $1933 / 1998$.

Imaginação e Criação na Infância. Ana Luiza Smolka comenta. Tradução Zoia Prestes. São Paulo: Editora Ática, 1930/ 2009.

WAJSKOP, Gisela. Brincar na pré-escola. São Paulo: Cortez, 1995. 